\title{
Characterization of the angiotensin (AT1b) receptor promoter and its regulation by glucocorticoids
}

\author{
Irina G Bogdarina, Peter J King and Adrian J L Clark \\ Centre for Endocrinology, Queen Mary University of London, Barts and the London School of Medicine and Dentistry, John Vane Science Centre, \\ Charterhouse Square, London EC1M 6BQ, UK \\ (Correspondence should be addressed to A J L Clark; Email: a.j.clark@qmul.ac.uk)
}

\begin{abstract}
Angiotensin II acts through two pharmacologically distinct receptors known as AT1 and AT2. Duplication of the AT1 receptor in rodents into At1a and b subtypes allows tissue-specific expression of the AT1b in adrenal and pituitary tissue. Adrenal expression of this receptor is increased in the offspring of rat mothers exposed to a low-protein diet and this is associated with the undermethylation of its promoter. This phenomenon is blocked by the inhibition of maternal glucocorticoid synthesis by metyrapone. We have mapped the transcriptional start site of the promoter and demonstrated that a $1.2 \mathrm{kbp}$ fragment upsteam of this site is effective in driving luciferase expression in mouse Y1 cells. A combination of bioinformatic analysis, electrophoretic mobility shift analysis (EMSA), and mutagenesis studies demonstrates: i) the presence of a putative TATA box and CAAT box; ii) the presence of three Sp1 response elements, capable of binding SP1; mutation of any pair of these sites effectively disables this promoter; iii) the presence of four potential glucocorticoid response elements which each bind glucocorticoid receptor in EMSA, although only two confer dexamethasone inhibition on the promoter; iv) the presence of two AP1 sites. Mutagenesis of the distal AP1 site greatly diminishes promoter function but this is also associated with the loss of dexamethasone inhibition. These studies will facilitate an understanding of the mechanisms by which fetal programming leads to long term alterations in gene expression and the development of adult disease.
\end{abstract}

Journal of Molecular Endocrinology (2009) 43, 73-80

\section{Introduction}

The renin-angiotensin system plays a major part in the regulation of salt and water metabolism and consequently of blood pressure in mammals. Key components of this system are the receptors for angiotensin. Two $G$ protein-coupled receptors (the AT1 and AT2 receptors) have been identified in mammals which have distinctive pharmacological and signal transducing characteristics (Clauser et al. 1996, Inagami 1999). However, the majority of the short-term salt and water regulatory functions are mediated through the AT1 receptor. In rodents, a duplication of the AT1 receptor gene has formed the ATla and b receptor subtypes (encoded by Agtrla and Agtr1b respectively). Although the ligand binding and signal transducing features of these two highly homologous receptors are indistinguishable, they do differ in their sites of expression, with the AT1b largely restricted to the adrenal cortex and pituitary (Kakar et al. 1992, Sandberg et al. 1992).

The physiological importance of the ATlb is not immediately obvious when studied in the mouse knockout models as compensatory increases in Agtrla expression and/or the function can obscure its role. Agtrlb-knockout animals have impaired thirst-sensing and drinking, but are not hypotensive. However, in Agtr1a-knockout animals, studies with an AT1 antagonist further reduced the blood pressure, and an angiotensin II pressor effect mediated by the AT1b was observed. These aspects are reviewed by Audoly et al. (2000).

The selective advantage of having functionally the same receptor derived from distinct genes at these sites is not clear, but one probable benefit is the opportunity for each subtype to be driven and regulated by different promoters. The more widely active Agtrla promoter has been characterized in some detail (Murasawa et al. 1993, 1995, Takeuchi et al. 1993, Bhat et al. 1994). However, little work has been reported on the rat Agtrlb promoter following its initial characterization (Guo \& Inagami 1994).

The Agtrlb is of interest to us in view of our previously reported finding that a maternal low-protein diet results in an increased expression of the adrenal Agtrlb by 1 week of age in offspring (Bogdarina et al. 2007). It has previously been shown in this model of fetal programming that the adrenal shows increased mineralocorticoid responsiveness to Ang II (McMullen et al. 2004, McMullen \& Langley-Evans 2005) and this increased expression of Agtrlb provides a potential mechanism for the hypertensive phenotype that 
develops after about 4 weeks of age in these animals (Langley-Evans 1997, 2000, Bertram \& Hanson 2002). We showed that the putative Agtr1b promoter was undermethylated in this model, which may account for the increased gene expression (Bogdarina et al. 2007). No significant changes in the expression of Agtrla or any other component of the renin-angiotensin system were found in any tissue studied at this early age.

Several theories for the development of fetal programming have been proposed (e.g. Simmons 2005, Fernandez-Twinn \& Ozanne 2006, Lévy-Marchal \& Czernichow 2006, Gluckman \& Hanson 2007). One of the most widely accepted hypotheses is that maternal stress resulting from various causes leads to increased fetal exposure to maternal glucocorticoids and hence long-term alteration in gene expression or cell number in offspring (Langley-Evans 1997, Bertram \& Hanson 2002). Since we have found that fetal programming leads to altered Agtr $1 b$ promoter methylation, we were particularly interested to investigate the possibility that glucocorticoids might alter DNA methylation of this gene. Administration of metyrapone, an inhibitor of corticosterone production, during the first 2 weeks of pregnancy in rats eating a low-protein diet is able to reverse the overexpression and to normalize the undermethylation of the Agtrlb gene (manuscript submitted). We have therefore set out to characterize this promoter in greater detail and in particular to investigate the mechanisms of any interaction with glucocorticoids which might in turn lead to alterations in methylation of this gene during development.

\section{Methods}

\section{Cell culture, transfections, and luciferase assay}

Mouse adrenocortical Y1 cells were maintained in high glucose DMEM/F10 medium (1:1) supplemented with $2.5 \%$ fetal bovine serum (FBS), 12\% horse serum (HS), and penicillin/streptomycin at $37^{\circ} \mathrm{C}$ and in $5 \%$ $\mathrm{CO}_{2}$. For transfection, $200 \mathrm{ng}$ of each plasmid were co-transfected with $20 \mathrm{ng}$ of the pRL-CMV Renilla control vector (Promega, Southampton, UK) into cells in 12-well plates using calcium phosphate precipitation. Thirty-six hours later the cells were washed with PBS, lysed and the promoter activity was measured using the Dual Luciferase reporter assay protocol (Promega) with results normalized to Renilla luciferase activity. All experiments were performed three times, each time in triplicate. For dexamethasone stimulation experiments the cells were washed in PBS and cultured in fresh DMEM/F10 supplemented with dextran-coated charcoal-treated FBS and HS. Cells were stimulated with $10^{-7} \mathrm{M}$ dexamethasone for $6 \mathrm{~h}$.

\section{DNA manipulations}

$5^{\prime}$-Rapid amplification of cDNA ends (RACE) was performed using GeneRacer kit (Invitrogen) according to the manufacturers instructions. Gel purified PCR products were cloned into the TOPO vector (Invitrogen) and sequenced.

Using rat adrenal genomic DNA as a template for PCR with primers (F-AGAGCTCCTTTCCATCTGTTTGTTTCTG/R_ GATAGATCTTCCCAAGGTGGCAAG), a $1.3 \mathrm{kbp}$ PCR product, containing the $5^{\prime}$-region of the Agtr1b promoter was cloned into SacI-BglII sites of pGL3-basic vector. This was subsequently digested with SacI and BamHI, the $1178 \mathrm{bp}$ fragment was gel purified and recloned into SacI-BglII sites of pGL3. This plasmid, pGL3AT1b was used in further experiments for site-directed mutagenesis of three CpG sites. pGL3AT1b was used as a PCR template to create serial $5^{\prime}$ deletions of the promoter containing a $202 \mathrm{bp}$ fragment or a $85 \mathrm{bp}$ fragment of the Agtrlb promoter. Both fragments were cloned into SacI and BglII digested pGL3 basic vector. Mutated CpG sites in the proximal Agtrlb promoter were generated using the QuikChange XL site-directed mutagenesis protocol (Stratagene, Cedar Creek, TX, USA). Mutations were confirmed by sequencing. For oligonucleotide sequences for PCR and mutagenesis, see the Supplementary Table 1 in the online version of the Journal of Molecular Endocrinology at http:/ /jme.endocrinologyjournals.org/content/vol43/issue2/.

\section{Electrophoretic mobility shift assays}

Preparation of nuclear extracts $-10^{6} \mathrm{HeLa}$ cells grown in DMEM with $10 \%$ FBS were lysed with Dignam buffer A (10 mM HEPES, pH 7.9, 1.5 mM MgCl, $10 \mathrm{mM} \mathrm{KCl,}$ $0.5 \mathrm{mM}$ dithiothreitol (DTT)) using $0 \cdot 1 \%$ NP-40. After isolation of nuclei by centrifugation, the proteins were extracted at $4^{\circ} \mathrm{C}$ for $60 \mathrm{~min}$ with Dignam buffer $\mathrm{C}$ (20 mM HEPES, pH 7.9, 25\% glycerol, 0.42 M NaCl, $1.5 \mathrm{mM} \mathrm{MgCl}_{2}, 0.2 \mathrm{mM}$ EDTA, $0.5 \mathrm{mM}$ DTT) in the presence of protease inhibitors $(0.5 \mathrm{mM}$ phenylmethylsulfonylfluorid, $1 \mathrm{mM}$ benzamidine, $30 \mathrm{mg} / \mathrm{ml}$ leupeptin, $5 \mathrm{mg} / \mathrm{ml}$ aprotinin, $5 \mathrm{mg} / \mathrm{ml}$ pepstatin). Nuclear extract was aliquoted and stored at $-80^{\circ} \mathrm{C}$.

Electrophoretic mobility shift assays (EMSAs) were performed in a $20 \mu \mathrm{l}$ binding reaction containing $10 \mu \mathrm{g}$ of the nuclear extract. Double-stranded oligonucleotides were labeled using $\left[\gamma^{-32} \mathrm{P}\right]$ ATP (Perkin Elmer, Waltham, MA, USA) and T4 polynucleotide kinase (New England Biolabs, Hitchin, Hertfordshire, UK) and purified from $15 \%$ PAGE. The reaction mixtures were incubated on ice for $10 \mathrm{~min}$, then ${ }^{32} \mathrm{P}$-labeled probe was added and the incubation was continued for another $30 \mathrm{~min}$ at RT. In supershift experiments, the nuclear extract was preincubated on ice with anti-Sp1 
antibody for $1 \mathrm{~h}$ before incubation with the ${ }^{32} \mathrm{P}$-labeled probe. DNA-protein complexes were separated on $4-5 \%$ non-denaturing polyacrylamide gel in $0.5 \times \mathrm{TBE}$ for $3 \mathrm{~h}$ at $200 \mathrm{~V}$ at $4{ }^{\circ} \mathrm{C}$ and subjected to autoradiography after drying. For competition experiments, 100 -fold molar excess of unlabeled competitor was pre-incubated with the nuclear extract for $15 \mathrm{~min}$ before labeled probe was added.

Antibodies used for supershift studies were anti-c-fos (K-25): sc-253, and anti-c-jun: sc-44 from Santa Cruz (Wembley, Middlesex, UK), anti-GR (PA1-510A) rabbit polyclonal antibody from Affinity BioReagents (Cambridge, UK) and anti-SP1 rabbit polyclonal antibody (2873-24) - a gift from Prof Steve Jackson, Gurdon Institute, Cambridge, UK.

\section{Results}

\section{Promoter mapping}

The start site of transcription of the rat Agtrlb gene was identified using the $5^{\prime}$ RACE technique (Fig. 1a). Sequencing of cloned extended products suggested the existence of several potential transcription start sites although the major site was located at position 1437 (Gene Bank Accession number U01033) and 11/20 sequenced clones revealed a start site in this position. Examination of $1.6 \mathrm{kbp}$ of genomic sequence upstream of this start site showed a sequence containing a probable TATA box (at $-27 \mathrm{bp}$ ), a weak CAAT box at $-59 \mathrm{bp}$ and $7 \mathrm{CpG}$ sites, of which three were located in the proximal promoter region. Analysis in silico using Transcription Element Search System (TESS, http:// www.cbil.upenn.edu/tess) suggested the presence of three putative binding sites for Sp1 $\left(5^{\prime}\right.$ end at $-43,-81$ and $-104 \mathrm{bp}$ relative to the transcriptional start site). CpG sites 1 and 2 are located in one of the Sp1 binding sites (site 2 - Sp1-2) and CpG site 3 in Sp1-3 (Fig. 1b). Binding sites for several other transcription factors including AP1 (position -98 and $-135 \mathrm{bp}$ ) were noted.

\section{Promoter function}

To assess the function of this putative promoter, a $1 \cdot 2 \mathrm{~kb}$ fragment was cloned into the pGL3 basic luciferase reporter vector. When transiently transfected into mouse Y1 adrenocortical cells significant luciferase activity was recorded. Deletion of this promoter to only the most proximal $202 \mathrm{bp}$ showed that most promoter activity was retained in this fragment, although further deletion to $85 \mathrm{bp}$ which removed both putative AP1 sites and the distal Sp1 site resulted in almost complete loss of activity (Fig. 2a). The three CpG sites of the proximal promoter $(-77,-72,-42)$ were individually or simultaneously mutated changing C for T. Mutation (a)

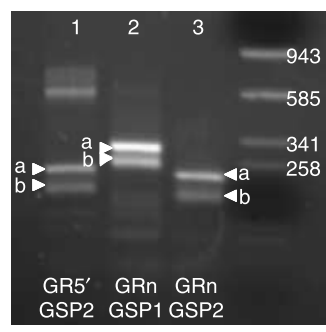

(b)

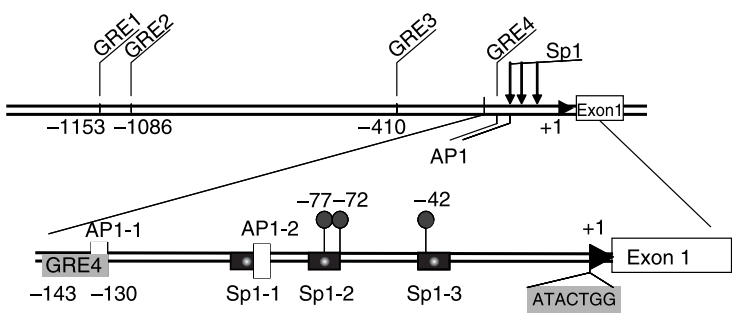

(c)

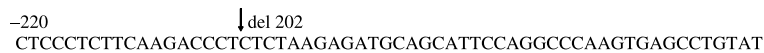

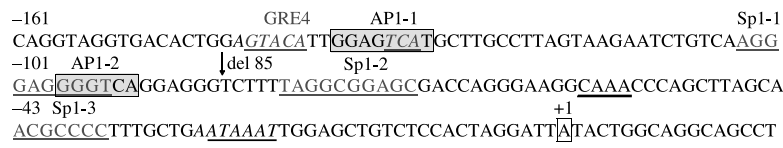

Figure 1 Mapping of the Agtr1b promoter. (a) Agarose gel showing the products of the $5^{\prime}$ RACE. Two major products ( $a$ and $\left.b\right)$ are found using independent reverse gene specific primers located at positions 639-654 (GSP1) and 537-559 (GSP2) of the Genebank genomic sequence S69961. Sequence analysis showed that the majority of clones derived from the 'a' band mapped a start site equivalent to position 1437 of the Genebank $5^{\prime}$ region and exon 1 sequence U01033. GR5' is GeneRacer $5^{\prime}$ primer and GRn is GeneRacer nested primer from Invitrogen. (b) A diagrammatic representation of $1.3 \mathrm{kbp}$ of promoter indicating the location of more distal GREs. Three CpGs sites located within the Sp1-2 and Sp1-3 are shown as closed circles. (c) DNA sequence of the putative proximal promoter showing the transcriptional start site $(+1)$, the probable TATA, CAAT box (both underlined), GRE4, AP1-1 and -2 (gray boxes), and three SP1 sites. Vertical arrows labeled del 202 and del 85 represent the $5^{\prime}$ ends of the two deletion constructs of the promoter studied in luciferase assays.

in CpG1 reduced luciferase activity to about $40 \%$ of wild-type, mutation in CpG2 had little effect, and mutation in CpG3 reduced the activity to about $5 \%$ of wild-type. Combinations of any two CpG mutations or all three obliterated promoter activity (Fig. 2b). We had previously reported that in vitro methylation of these CpG sites resulted in complete loss of promoter activity (Bogdarina et al. 2007).

\section{EMSA}

All three of the proximal promoter CpG sites lie within the predicted Sp1 sites Sp1-2 or Sp1-3. Evidence for the interaction with Sp1 was sought by EMSA using 
(a)

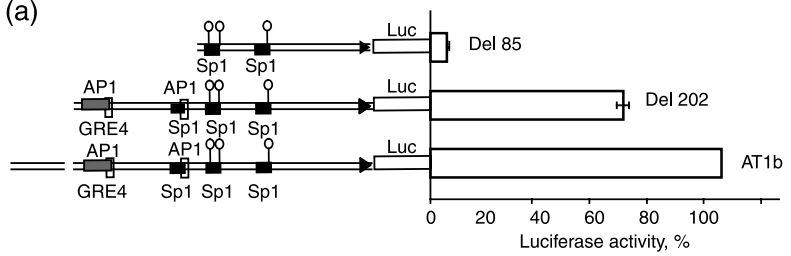

(b)

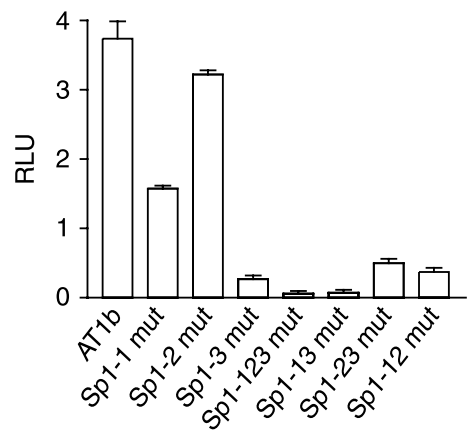

Figure 2 Function of the Agtr1b promoter in Y1 cells. (a) The full length, del 202, and del 85 promoter fragments were expressed in mouse $Y 1$ cells and promoter activity monitored using the Dual Luciferase system. Loss of sequences upstream of Sp1-2 results in greatly reduced promoter function. (b) Functional analysis of the full length promoter and derivatives containing mutations of the Sp1 sites is shown in (a). Mut1 is a mutation in the Sp1-2 site at positions -77 , mut2 is a mutation in the Sp1-2 site at -72 , and mut3 is a mutation in the Sp1-3 site at -42 . Mut 123 is a combination of all three mutations, and mut13, mut23, and mut12 mutations in the pairs of $\mathrm{CpG}$ sites so identified. All mutations represent a replacement of a $\mathrm{C}$ by $\mathrm{T}$.

HeLa cell nuclear extracts and oligonucleotides corresponding to Sp1-1, 2 or 3. All probes bind a complex of a similar mobility to that which binds a consensus Sp1 site (Fig. 3a - arrowed). A mutated Sp1-2 or Sp1-3 oligonucleotide was unable to bind a complex (Fig. 3a). One hundred-fold molar excess of the consensus Sp1 sequence effectively competes for complex binding on both these Sp1 probes (Fig. 3b). The mutant consensus sequence or mutant Sp1-2 or Sp1-3 sequence was unable to compete (Fig. 3b). Similar results are found using Y1 cell nuclear extracts (data not shown). Further evidence that this factor was $\mathrm{Sp} 1$ was sought using supershift with Sp1 antibodies. As can be seen in Fig. 3c, complexes formed with both probes and the consensus Spl probe show supershift. We had previously shown that the influence of each of these CpG sites on the promoter function was significantly reduced when methylated in vitro (Bogdarina et al. 2007). We therefore investigated whether Sp1 binding was influenced by methylation using specifically methylated probes in EMSA. In all cases when each of the CpG sites were methylated on both strands a complex migrating as for the unmethylated probe was seen and was supershifted by Sp1 antibody. Therefore, alternative mechanisms such as methyl-DNA binding proteins

binding to these methylated CpG sites are more likely to explain the inhibition of gene expression associated with methylation.

\section{Glucocorticoid regulation}

Using Y1 cells transfected with the full length Agtrlbluciferase vector pGL3AT1b, it was possible to demonstrate a potent suppressive effect of $6 \mathrm{~h}$ treatment with dexamethasone on luciferase activity. Dose response studies indicated an $\mathrm{IC}_{50}$ of $4 \cdot 4$ $\times 10^{-10}$ M (Fig. 4a).

To investigate whether the glucocorticoid effect was likely to be mediated through the putative GREs their ability to bind glucocorticoid receptor was investigated by EMSA. This confirmed that all four GREs bound a complex with similar mobility to that formed with a consensus GRE, and that a 100-fold excess of a consensus GRE competed these away. Addition of dexamethasone $\left(10^{-7} \mathrm{M}\right)$ to the culture medium for $6 \mathrm{~h}$ did not influence the intensity or size of complex formation (Fig. 4b). However, site-directed mutagenesis of GRE1 and 3, but not GRE2 and 4 in the context of the full length promoter led to loss of significant glucocorticoid responsiveness (Fig. 4c),

(a)

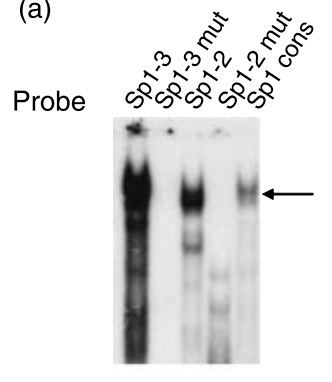

(c)

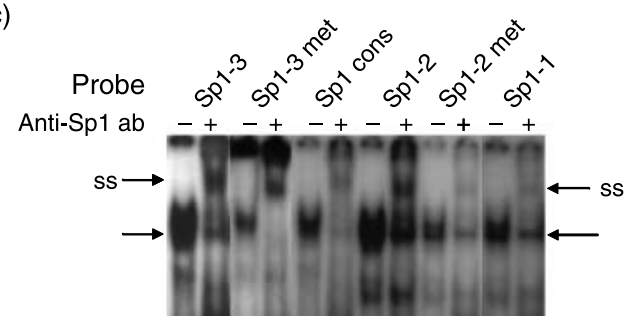

Figure $3 \mathrm{Sp} 1$ binding to proximal promoter elements. (a) EMSA using a consensus Sp1 or Sp1-2 or Sp1-3 as probes. All probes bind a similar sized complex (arrowed) although mutated Sp1-2 or Sp1-3 fail to bind. (b) Sp1-2 and Sp1-3 probes are competed by a consensus Sp1 sequence, but not by mutant sequences. (c) The consensus Sp1 and Sp1-1, -2, and -3 probes are supershifted by antibody to Sp1 (arrow labeled ss). DNA methylation of Sp1-2 or Sp1-3 (labeled SP1-2met and Sp1-3met) does not reduce complex formation (unlabeled arrow) or supershifted band after pre-incubation with antibody. 
suggesting that the glucocorticoid effect was mediated in part through these two sites (GRE1 and 3) acting as a negative GRE.

An alternative mechanism for glucocorticoid inhibition of gene expression is that it may be mediated through an AP1 site. Two consensus AP1 sites are present in the proximal promoter, one of which (AP1-2) overlaps Sp1-1 site, whilst the other (AP1-1) overlaps GRE4. EMSA demonstrated that the putative

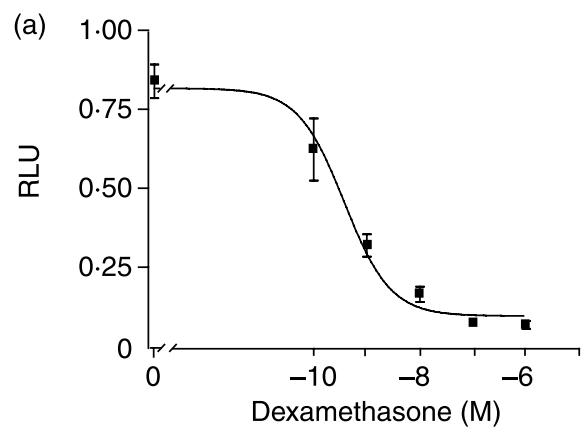

(b)
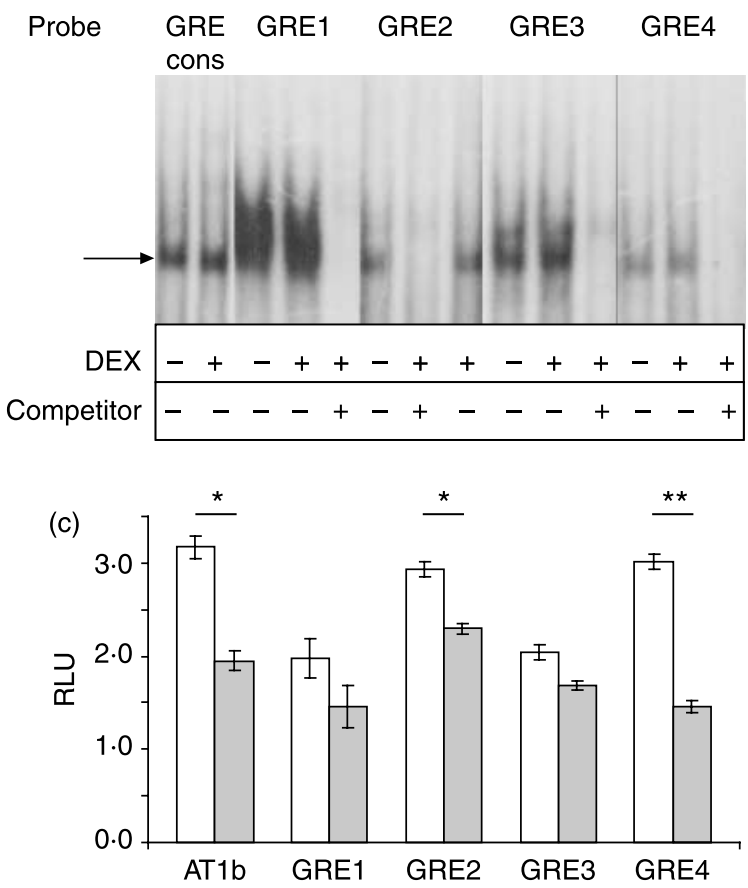

Figure 4 Glucocorticoid responsiveness of the proximal promoter. (a) The full length promoter-luciferase reporter shows a dose dependent inhibition by dexamethasone in Y1 cells. (b) EMSA with a consensus GRE, or GRE1-4 from the Agtr $1 b$ shows a similar complex formation (arrowed) which is not significantly altered by the pre-treatment of cells with dexamethasone. All of the Agtr1b GRE probes show successful competition by a consensus GRE. (c) The Agtr1b promoter reporter still shows adequate function in the presence of mutations of each of the GREs, and glucocorticoid inhibition is retained with the GRE2 and GRE4 mutants, but is lost when GRE1 and 3 are mutated. RLU, relative light units. ${ }^{\star} P<0.05 ;{ }^{\star \star} P<0.001$. (a)

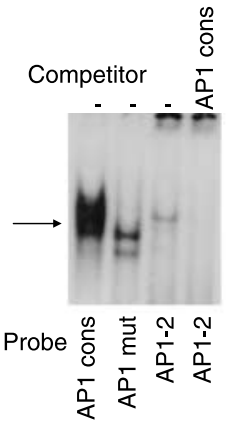

(c)

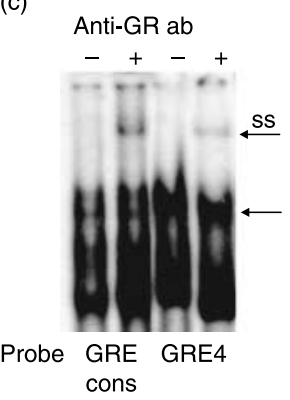

(b)

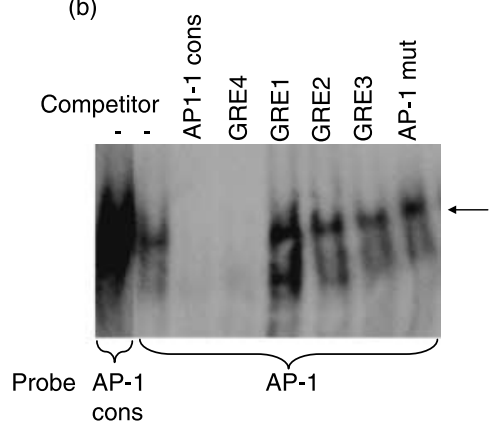

(d)

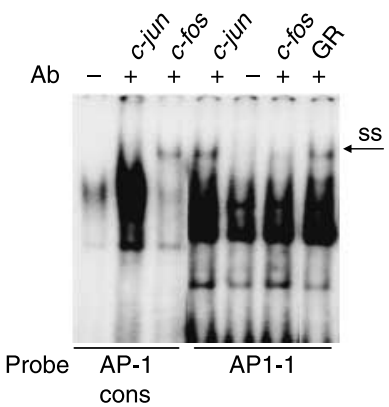

Figure 5 Characterization of AP1 sites. (a) EMSA demonstrating that complexes formed on a consensus AP1 sequence and AP1-2 migrate as a complex with similar mobility, and that a consensus oligonucleotide effectively competes with AP1-2 for binding. Note that the mutant AP1 sequence also reveals a non-specific doublet complex of greater mobility than that formed with AP1. (b) EMSA demonstrating that complexes formed on AP1-1 and a consensus AP1 oligonucleotide migrate with similar mobility, but that AP1-1 binding is competed by a consensus oligonucleotide or by the GRE4 oligonucleotide, but not by a mutant consensus AP1 fragment or the other GRE oligonucleotides. (c) The GRE4 probe binds a complex that is supershifted by glucocorticoid receptor antibody (arrow labeled ss), similar to that observed with the consensus GR probe. (d) The AP1-1 probe binds a complex that is supershifted with anti- $c$-jun and anti-GR antibodies, and to a lesser extent with anti-c-fos antibody.

AP1-2 site formed a complex that had similar mobility to that of a consensus AP1 site. Mutation of this site prevented formation of this complex which was also competed by a consensus AP1 oligonucleotide (Fig. 5a). The AP1-1 site also formed a similar complex which was competed by a AP1 consensus oligonucleotide and by GRE4, but not by GRE1, GRE2, GRE3 or mutant consensus AP1 (Fig. 5b). Supershift experiments with anti-c-fos, anti-c-jun, and anti-GR suggested AP1 and GR could interact with the AP1-1 sequence (Fig. 5d).

Dexamethasone responsiveness was not affected by mutagenesis of AP1-1. Mutagenesis of AP1-2 resulted in greatly reduced activity of the promoter and this was associated with loss of dexamethasone inhibition (Fig. 6). 


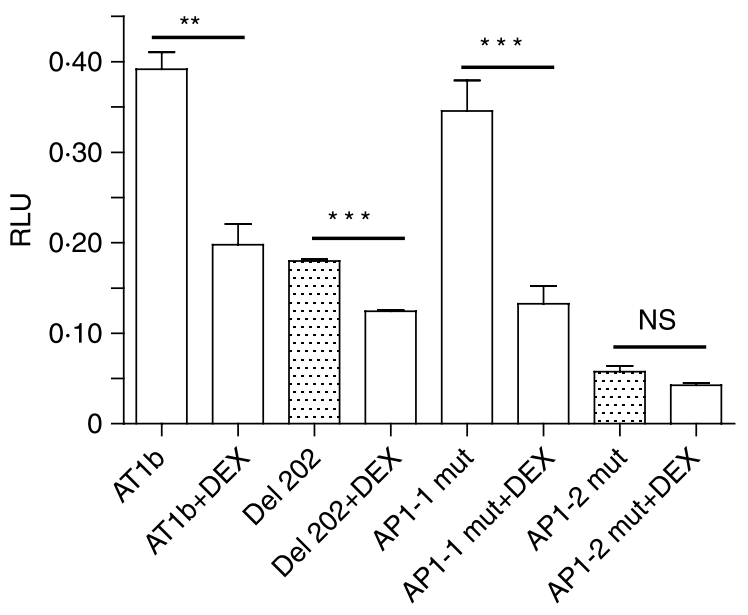

Figure 6 Role of AP1 sites in dexamethasone responsiveness. Dexamethasone $\left(10^{-6} \mathrm{M}\right)$ inhibited the activity of constructs containing the full length promoter and the del 202 construct with and without a mutated AP1-1 site. Mutation of the AP1-2 site resulted in greatly reduced promoter activity and no evidence of additional dexamethasone suppression of this construct was observed. Statistical comparison was made using Two-way Anova with a Bonnferroni correction. ${ }^{* \star} P<0.001 ;{ }^{* \star *} P<0.0001$; NS, not significant $(P>0.05)$.

\section{Discussion}

As outlined in the Introduction, our interest in the Agtr1b promoter is driven by our observations on its expression in fetal programming models of hypertension. One candidate mechanism for this phenomenon is that stress-induced maternal glucocorticoid excess may provide a common pathway linking various maneuvers that ultimately lead to similar cardiovascular and metabolic endpoints in the adult. Consequently, we were particularly interested to observe the effects, if any, of glucocorticoids on expression of the Agtrlb gene. Previously, Chansel et al. (1996) reported that dexamethasone reduced Agtr1b mRNA expression in rat mesangial cells, but no effect of dexamethasone was observed in vascular smooth muscle cells (Guo et al. 1995). We hypothesized that glucocorticoid targeting of the Agtrlb gene may also direct reduced methylation of the gene, and if so, it would be of great interest to identify the mechanism of this effect.

In order to achieve this it was necessary to characterize this promoter and its function in the adrenocortical cells. Previous studies (Guo \& Inagami 1994) had identified a putative promoter region and suggested that it may contain glucocorticoid response elements, though these were not found to be functional in vascular smooth muscle cells, which do not express this receptor endogenously. In this work we have characterized the $5^{\prime}$ end of the gene using the RACE technique and used this information to re-define the promoter as a probable TATA-box, CAAT-box, and Sp1 containing promoter. We have shown that Sp1 binds to three consensus Spl sites and this is required for a normal expression of the gene. Mutation of $\mathrm{CpG}$ sites 1 and 3 significantly reduces gene expression whereas mutation of $\mathrm{CpG}$ site 2 has little effect. However, methylation of these CpG sites does not reduce Sp1 binding, as is the case for most, but not all, Sp1 binding sites (Zhu et al. 2003, Liedtke et al. 2005).

The $1.2 \mathrm{kbp}$ of promoter studied is clearly capable of signaling a negative glucocorticoid effect in $\mathrm{Y} 1$ cells with an $\mathrm{IC}_{50}$ characteristic of a glucocorticoid receptor mediated effect. By sequence comparison there are four potential consensus GREs in this promoter, two of which correspond to those identified previously (Guo et al. 1995). Two of these, GRE1 and 3 appear to mediate in part the negative glucocorticoid effect. However, significant glucocorticoid inhibition was also seen with the proximal $202 \mathrm{bp}$ of promoter which only includes GRE4. This GRE does not seem to influence luciferase expression directly, but closely overlies one of the two AP1 sites in this region. As there are several examples of negative glucocorticoid effects being mediated via protein-protein interaction between GR and AP1 (Yang-Yen et al. 1990, Heck et al. 1994, Wargnier et al. 1998, Tuckermann et al. 1999) this alternative was investigated. Mutagenesis of AP1-1 had a relatively small effect on gene expression and the glucocorticoid repression was retained. Mutagenesis of AP1-2 led to substantial loss of expression of the gene, which was accompanied by loss of glucocorticoid inhibition raising the possibility that this is an additional means of glucocorticoid inhibition.

Although the acute negative glucocorticoid regulation observed in these promoter studies might appear to contradict the long-term enhancement of function observed in programmed animals, we believe the latter effect is mediated by reduced methylation. Conceivably the interaction of this promoter with the GR may influence the deposition of methylated sites during the critical period of development at which this occurs.

A further observation of interest is that the Sp1-3 sequence in addition to consensus sites for GAGA factor and zeste in exon 1 form a potential polycomb response element (PRE). PREs are of particular importance in early development where, in mammalian cells, they may

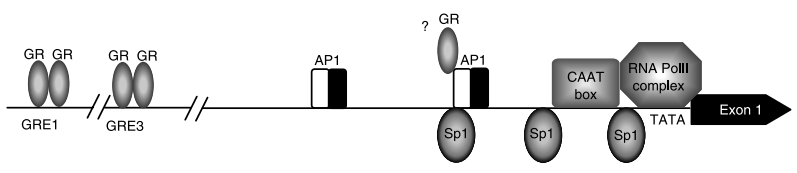

Figure $7 \mathrm{~A}$ diagrammatic representation of the key elements of the rat $A g t r 1 b$ promoter (not drawn to scale). The interaction between GR and the proximal AP1 site (AP1-2) is speculative. 
bind several proteins that can influence the chromatin structure in the surrounding vicinity as a result of histone methylation (Simon \& Tamkun 2002, Lomberk \& Urrutia 2005, Schwartz \& Pirrotta 2007, Vasanthi \& Mishra 2008). Susceptibility of a DNA region to methylation in the course of development may depend on the chromatin structure and thus be influenced by PRE activity. To what extent maternal glucocorticoids can influence PRE occupancy is not known.

In summary, we report the characterization of the Agtr1b promoter in Y1 cells, and glucocorticoid inhibition of expression has been identified acting in part through upstream promoter GREs as well as other incompletely clear mechanisms. Our findings are summarized in Figure 7. How this relates to the function of this promoter in the perinatal rat adrenal and its pattern of developmental methylation is not clear.

\section{Declaration of interest}

The authors declare that there is no conflict of interest that could be perceived as prejudicing the impartiality of the research reported.

\section{Funding}

This work was funded by a grant from the British Heart Foundation.

\section{Acknowledgements}

We are grateful to Prof Steve Jackson (Gurdon Institute, Cambridge) for the gift of Sp1 antibody.

\section{References}

Audoly LP, Olivierio MI \& Coffman TH 2000 Insights into the functions of type 1 (AT1) angiotensin II receptors provided by gene targeting. Trends in Endocrinology and Metabolism 11 263-269.

Bertram CE \& Hanson MA 2002 Prenatal programming of postnatal endocrine responses by glucocorticoids. Reproduction 124 459-467.

Bhat GJ, Thekkumkara TJ, Thomas WG, Conrad KM \& Baker KM 1994 Angiotensin II stimulates sis-inducing factor-like DNA binding activity. Evidence that the AT1A receptor activates transcription factor-Stat91 and/or a related protein. Journal of Biological Chemistry 269 31443-31449.

Bogdarina I, Welham S, King PJ, Burns SP \& Clark AJ 2007 Epigenetic modification of the renin-angiotensin system in the fetal programming of hypertension. Circulation Research 100 520-526.

Chansel D, Llorens-Cortes C, Vandermeersch S, Pham P \& Ardaillou R 1996 Regulation of angiotensin II receptor subtypes by dexamethasone in rat mesangial cells. Hypertension 27 867-874.

Clauser E, Curnow KM, Davies E, Conchon S, Teutsch B, Vianello B, Monnot C \& Corvol P 1996 Angiotensin II receptors: protein and gene structures, expression and potential pathological involvements. European Journal of Endocrinology 134 403-411.

Fernandez-Twinn DS \& Ozanne SE 2006 Mechanisms by which poor early growth programs type-2 diabetes, obesity and the metabolic syndrome. Physiology and Behaviour 88 234-243.
Gluckman PD \& Hanson MA 2007 Developmental plasticity and human disease: research directions. Journal of Internal Medicine $\mathbf{2 6 1}$ $461-471$.

Guo DF \& Inagami T 1994 The genomic organization of the rat angiotensin II receptor AT1B. Biochimica et Biophysica Acta 1218 91-94.

Guo DF, Uno S \& Inagami T 1995 Steroid hormones upregulate rat angiotensin II type 1A receptor gene: role of glucocorticoid responsive elements in rat angiotensin II type 1A promoter. Journal of Steroid Biochemistry and Molecular Biology 53 69-73.

Heck S, Kullmann M, Gast A, Ponta H, Rahmsdorf HJ, Herrlich P \& Cato AC 1994 A distinct modulating domain in glucocorticoid receptor monomers in the repression of activity of the transcription factor AP-1. EMBO Journal 13 4087-4095.

Inagami T 1999 Molecular biology and signaling of angiotensin receptors: an overview. Journal of the American Society of Nephrology 10 S2-S7.

Kakar SS, Sellers JC, Devor DC, Musgrove LC \& Neill JD 1992 Angiotensin II type-1 receptor subtype cDNAs: differential tissue expression and hormonal regulation. Biochemical and Biophysical Research Communications 183 1090-1096.

Langley-Evans SC 1997 Intrauterine programming of hypertension by glucocorticoids. Life Sciences 60 1213-1221.

Langley-Evans SC 2000 Critical differences between two low protein diet protocols in the programming of hypertension in the rat. International Journal of Food Sciences and Nutrition 51 11-17.

Lévy-Marchal C \& Czernichow P 2006 Small for gestational age and the metabolic syndrome: which mechanism is suggested by epidemiological and clinical studies? Hormone Research 65 123-130.

Liedtke C, Zschemisch NH, Cohrs A, Roskams T, Borlak J, Manns MP \& Trautwein C 2005 Silencing of caspase-8 in murine hepatocellular carcinomas is mediated via methylation of an essential promoter element. Gastroenterology 129 1602-1615.

Lomberk G \& Urrutia R 2005 The family feud: turning off Sp1 by Sp1like KLF proteins. Biochemical Journal 392 1-11.

McMullen S, Gardner DS \& Langley-Evans SC 2004 Prenatal programming of angiotensin II type 2 receptor expression in the rat. British Journal of Nutrition 91 133-140.

McMullen S \& Langley-Evans SC 2005 Maternal low-protein diet in rat pregnancy programs blood pressure through sex-specific mechanisms. American Journal of Physiology. Regulatory, Integrative and Comparative Physiology 288 R85-R90.

Murasawa S, Matsubara H, Urakami M \& Inada M 1993 Regulatory elements that mediate expression of the gene for the angiotensin II type la receptor for the rat. Journal of Biological Chemistry $\mathbf{2 6 8}$ 26996-27003.

Murasawa S, Matsubara H, Mori Y, Kijima K, Maruyama K \& Inada M 1995 Identification of a negative cis-regulatory element and trans-acting protein that inhibit transcription of the angiotensin II type 1a receptor gene. Journal of Biological Chemistry 270 24282-24286.

Sandberg K, Ji H, Clark AJ, Shapira H \& Catt KJ 1992 Cloning and expression of a novel angiotensin II receptor subtype. Journal of Biological Chemistry 267 9455-9458.

Schwartz YB \& Pirrotta V 2007 Polycomb silencing mechanisms and the management of genomic programmes. Nature Reviews. Genetics 8 9-22.

Simmons R 2005 Developmental origins of adult metabolic disease: concepts and controversies. Trends in Endocrinology and Metabolism 16 390-394.

Simon JA \& Tamkun JW 2002 Programming off and on states in chromatin: mechanisms of Polycomb and trithorax group complexes. Current Opinion in Genetics and Development 12 210-218.

Takeuchi K, Alexander RW, Nakamura Y, Tsujino T \& Murphy TJ 1993 Molecular structure and transcriptional function of the rat vascular ATla angiotensin receptor gene. Circulation Research 73 612-621. 
Tuckermann JP, Reichardt HM, Arribas R, Richter KH, Schutz G \& Angel P 1999 The DNA binding-independent function of the glucocorticoid receptor mediates repression of AP-1-dependent genes in the skin. Journal of Cell Biology 147 1365-1370.

Vasanthi D \& Mishra RK 2008 Epigenetic regulation of genes during development: a conserved theme from flies to mammals. Journal of Genetics and Genomics 35 413-429.

Wargnier A, Lafaurie C, Legros-Maida S, Bourge JF, Sigaux F, Sasportes M \& Paul P 1998 Down-regulation of human granzyme $\mathrm{B}$ expression by glucocorticoids. Dexamethasone inhibits binding to the Ikaros and AP-1 regulatory elements of the granzyme B promoter. Journal of Biological Chemistry 273 35326-35331.
Yang-Yen HF, Chambard JC, Sun YL, Smeal T, Schmidt TJ, Drouin J \& Karin M 1990 Transcriptional interference between c-Jun and the glucocorticoid receptor: mutual inhibition of DNA binding due to direct protein-protein interaction. Cell 62 1205-1215.

Zhu WG, Srinivasan K, Dai Z, Duan W, Druhan LJ, Ding H, Yee L, Villalona-Calero MA, Plass C \& Otterson GA 2003 Methylation of adjacent CpG sites affects Sp1/Sp3 binding and activity in the p21(Cip1) promoter. Molecular and Cellular Biology 23 4056-4065.

Received in final form 22 April 2009

Accepted 1 May 2009

Made available online as an Accepted Preprint 1 May 2009 